\title{
Commentary \\ Tight glucose control: should we move from intensive insulin therapy alone to modulation of insulin and nutritional inputs?
}

\author{
Pierre Kalfon ${ }^{1}$ and Jean-Charles Preiser ${ }^{2}$
}

\begin{abstract}
${ }^{1}$ Department of General Intensive Care, Hospital of Chartres, 34, rue du Docteur Maunoury, 28000 Chartres, France ${ }^{2}$ Department of Intensive Care, University Hospital of Liege, Domaine du Sart Tilman B 35, B-4000 Liege 1, Belgium
\end{abstract}

Corresponding author: Pierre Kalfon, pkalfon@ch-chartres.fr

Published: 19 June 2008

This article is online at http://ccforum.com/content/12/3/156

(C) 2008 BioMed Central Ltd

See related research by Chase et al., http://ccforum.com/content/12/2/R49
Critical Care 2008, 12:156 (doi:10.1186/cc6915)

\begin{abstract}
The report by Chase and coworkers in the previous issue of Critical Care describes the implementation into clinical practice of the Specialized Relative Insulin Nutrition Table (SPRINT) for tight glycaemic control in critically ill patients. SPRINT is a simple, wheel-based system that modulates both insulin rate and nutritional inputs. It achieved a better glycaemic control in a severely ill critical cohort than their previous method for glycaemic control in a matched historical cohort. Reductions in mortality were also observed.
\end{abstract}

In the previous issue of Critical Care, Chase and coworkers [1] reported on their implementation into clinical practice and evaluation of the Specialized Relative Insulin Nutrition Table (SPRINT). This is an improved protocol in the form of a wheel-based system to control blood glucose levels and nutritional intakes in intensive care patients, which was developed a few years ago $[2,3]$.

Blood glucose has become a key biological parameter in critical care since publication of the study conducted by van den Berghe and colleagues [4], who demonstrated decreased mortality in surgical intensive care patients in association with tight glycaemic control (TGC), based on intensive insulin therapy. However, two negative studies were recently reported, which were interrupted early because of high rates of severe hypoglycaemia, namely the VISEP study [5] and the as yet unpublished Glucontrol trial. Hence, there is currently much debate regarding the actual benefits of such a strategy in intensive care patients in terms of outcomes [6]. It is also uncertain whether the results of the ongoing multicentre, open label, randomized controlled trial NICE SUGAR [7] of the effects of blood glucose management on 90-day all-cause mortality in a heterogeneous population of intensive care unit (ICU) patients will resolve remaining concerns about TGC in the ICU. Included among these concerns is the key issue of what is the most appropriate algorithm to achieve the desired blood glucose range.

The major focus of the study conducted by Chase and colleagues was on the method to achieve a predetermined blood glucose range by modulating both insulin infusion rate and nutritional inputs. As with the other reported studies comparing protocols, efficacy was evaluated by comparison with historical control patients. However, although the study reported by Chase and coworkers was conducted with great care and rigour, it is but another case-control retrospective comparative study.

Nevertheless, there is a clear need to introduce efficient tools that will help clinicians and nursing staff to control blood glucose levels in ICU patients, because hyperglycaemia superior to $10 \mathrm{mmol} / \mathrm{l}$ is no longer considered to be acceptable. Studies are required to provide clinicians with recommendations on the evaluation and comparison of the various protocols currently in use or that are soon to become available $[8,9]$.

Benchmarking of TGC protocols must take in account all the dimensions of efficiency : performance, risk for severe hypoglycaemia, practical aspects (ease of use, training time and required materials prior to implementation, error rate), integrated continuous monitoring, nursing workload (evaluated on the mean time between controls). Furthermore the best way to compare performance is controversial: is it the time with glucose within a common target range, the hyperglycaemia index, the recently described glycaemic penalty index [11], or the variability that would be associated with outcome [12]?

With respect to this efficiency analysis, SPRINT appears to be effective. This raises the question of whether the efficacy

ICU = intensive care unit; SPRINT = Specialized Relative Insulin Nutrition Table; TGC $=$ tight glycaemic control. 
results from instructions regarding nutritional intake, allowing insulin infusion rates to be limited to a level lower than usual, or from the intrinsic quality of the algorithm used, which is based on the glucose-insulin regulatory system model (capturing insulin utilization rate, insulin losses and saturation dynamics). Also, SPRINT is apparently associated with few severe hypoglycemia events, which contrasts with the high rate of severe hypoglycaemic episodes reported in the second Leuven study [13]. Finally, SPRINT should be relatively simple to implement in numerous ICUs as a paperbased protocol, presented in an original form using a wheel, without need for computational resources.

Weaknesses of SPRINT rest in its inability to monitor parameters related to the quality of glucose control as SPRINT is a paper-based protocol. Most importantly, despite the favourable subjective opinions of care givers, SPRINT may not reduce workload because it requires measurements every hour or 2 hours.

Ultimately, evaluation of any TGC protocol must also include an assessment of its ability to be implemented easily and safely in another ICU that did not participate in its development [14]. The monocentric study of Chase and coworkers [1] may not ensure the 'exportability' of their TGC protocol.

The debate continues about the real benefits of TGC, with numerous questions being asked. What is the optimal target range? Which patients will benefit the most? When during the ICU stay should TGC be applied and to derive which benefits? Which is the best method to control glucose level intensive insulin therapy, and/or limitation of nutritional intakes during acute phase, and/or antidiabetic drugs? However, the competition to develop the ideal tool with which to control blood glucose levels in the ICU and perhaps throughout the hospital stay has begun, involving multidisciplinary teams of physicians and engineers who have specialized in control systems (feedback control or model predictive control [15]).

\section{Competing interests}

J-CP declares that he has no competing interests. PK declares that he holds shares of LK2 (Saint-Avertin, France). PK serves as consultant to LK2.

\section{References}

1. Chase JG, Shaw G, Le Compte A, Lonergan T, Willacy M, Wong XW, Lin J, Lotz T, Lee D, Hann C: Implementation and evaluation of the SPRINT protocol for tight glycaemic control in critically ill patients: a clinical practice change. Crit Care 2008, 12:R49.

2. Wong XW, Singh-Levett I, Hollingsworth LJ, Shaw GM, Hann CE, Lotz T, Lin J, Wong OS, Chase JG: A novel, model-based insulin and nutrition delivery controller for glycemic regulation in critically ill patients. Diabetes Technol Ther 2006, 8:174-190.

3. Wong XW, Chase JG, Shaw GM, Hann CE, Lotz T, Lin J, SinghLevett I, Hollingsworth LJ, Wong OS, Andreassen S: Model predictive glycaemic regulation in critical illness using insulin and nutrition input: a pilot study. Med Eng Phys 2006, 28:665-681.

4. van den Berghe $G$, Wouters $P$, Weekers F, Verwaest $C$, Bruyninckx F, Schetz M, Vlasselaers D, Ferdinande P, Lauwers $P$, Bouillon R: Intensive insulin therapy in the critically ill patients.
N Engl J Med 2001, 345:1359-1367.

5. Brunkhorst FM, Engel C, Bloos F, Meier-Hellmann A, Ragaller M, Weiler N, Moerer O, Gruendling M, Oppert M, Grond S, Olthoff D, Jaschinski U, John S, Rossaint R, Welte T, Schaefer M, Kern P, Kuhnt E, Kiehntopf M, Hartog C, Natanson C, Loeffler M, Reinhart K; German Competence Network Sepsis (SepNet): Intensive insulin therapy and pentastarch resuscitation in severe sepsis. N Engl J Med 2008, 358:125-139.

6. Merz TM, Finfer S: Pro/con debate: is intensive insulin therapy targeting tight blood glucose control of benefit in critically ill patients? Crit Care 2008, 12:212.

7. Bellomo R, Egi M: Glycemic control in the intensive care unit: why we should wait for NICE-SUGAR. Mayo Clin Proc 2005, 80:1546-1548.

8. Wilson M, Weinreb J, Hoo GW: Intensive insulin therapy in critical care: a review of 12 protocols. Diabetes Care 2007, 30: 1005-1011.

9. Pittas AG, Siegel RD, Lau J: Insulin therapy and in-hospital mortality in critically ill patients: systematic review and metaanalysis of randomized controlled trials. JPEN J Parenter Enteral Nutr 2006, 30:164-172.

10. Vogelzang M, van der Horst IC, Nijsten MW: Hyperglycaemic index as a tool to assess glucose control: a retrospective study. Crit Care 2004, 8:R122-R127.

11. Van Herpe T, De Brabanter J, Beullens M, De Moor B, Van den Berghe G: Glycemic penalty index for adequately assessing and comparing different blood glucose control algorithms. Crit Care 2008, 12:R24.

12. Egi M, Bellomo R, Stachowski E, French CJ, Hart G: Variability of blood glucose concentration and short-term mortality in critically ill patients. Anesthesiology 2006, 105:244-252.

13. Van den Berghe G, Wilmer A, Hermans G, Meersseman W, Wouters PJ, Milants I, Van Wijngaerden E, Bobbaers H, Bouillon R: Intensive insulin therapy in the medical ICU. N Engl J Med 2006, 354:449-461.

14. Krinsley JS, Preiser JC: Moving beyond tight glucose control to safe effective glucose control. Crit Care 2008, 12:149.

15. Hovorka R, Kremen J, Blaha J, Matias M, Anderlova K, Bosanska L, Roubicek T, Wilinska ME, Chassin LJ, Svacina S, Haluzik M: Blood glucose control by a model predictive control algorithm with variable sampling rate versus a routine glucose management protocol in cardiac surgery patients: a randomized controlled trial. J Clin Endocrinol Metab 2007, 92:2960-2964. 